\title{
Study on Development of Renewable Energy in Rural China and Driven Factors Based on A DEA Model
}

\author{
Caiqing Zhang ${ }^{1}$, \\ ${ }^{1}$ Department of Economics and Management ,North \\ China Electric Power University, \\ Baoding 071000, China
}

\author{
Bo Ruan ${ }^{1}$ \\ ${ }^{1}$ Department of Economics and Management ,North \\ China Electric Power University, \\ Baoding 071000, China
}

\begin{abstract}
In November in 2009, China announced a new carbon intensity reduction target in 2020 year to manifest the commitment of the Chinese government to dealing with climate change. The development of renewable energy is not only an important measure to accelerate the adjustment of energy structure, but also a key measure to decrease the Carbon emissions. This paper firstly introduces the theory of Data Envelopment Analysis. Then, we establish a development prospects model of Chinese rural renewable energy, and make a empirical analysis based on the data of Chinese 27 provinces for the year 2012. The results show that development of most rural renewable energy is not perfect, there is a big space for development. Furthermore, the finding shows that input indicators, including population, consumption and education are the main factors that affect the development of renewable energy in rural China.
\end{abstract}

Keywords: DEA model; rural; renewable energy; correlation

\section{Introduction}

"The Twelfth Five Year Plan" has put forward a new reform of energy production and utilization, which can be crystallize as the target of increase the of proportion nonfossil energy consumption to $15 \%$ and reduce carbon emissions per unit of GDP range from $40 \%$ to $50 \%$ by $2020^{[1]}$. Currently, fossil energy consumption in rural China accounts for a large proportion of total energy consumption, and characterized by low efficiency, which indicates that the rural area possesses resources and environmental conditions, essential to the development of renewable energy in rural China ${ }^{[2,3]}$. Data envelopment analysis (DEA) is one of the applications of the linear programming model, which is often used to measure the relative efficiency of the operating units with the same objectives ${ }^{[4]}$. In this paper, the DEA model is used to construct a evaluation model of rural renewable energy development in 27 rural regions of China, then analyze the factors that influence the development of renewable energy.

\section{Renewable energy development evaluation model}

\subsection{DEA model}

The basic idea of DEA is to study the effectiveness of input from the point of constant output, or to study the validity of the output from the point of constant input. CRR model is the traditional form of the DEA model, which cannot separate the technical efficiency from scale efficiency. The technical efficiency will be divided into scale efficiency and net technical efficiency, when we use a $\mathrm{C}^{2} \mathrm{GS}^{2}$ model which is an improvement to the traditional model ${ }^{[5,6]}$. The $\mathrm{C}^{2} \mathrm{GS}^{2}$ model is show as the following function:

$$
\begin{cases} & \min \theta=V_{D} \\ \text { s.t. } & \sum_{j=1}^{n} X_{j} \lambda_{j}+S^{-}=\theta X_{j_{0}} \\ & \sum_{j=1}^{n} Y_{j} \lambda_{j}-S^{+}=\theta Y_{j_{0}} \\ & \sum_{j=1}^{n} \lambda_{j}=1 \\ & \lambda_{j} \geq 0, \quad j=1, \cdots, n \\ & S^{-} \geq 0, S^{+} \geq 0\end{cases}
$$

Where $X_{j}=\left(x_{1 j}, x_{2 j}, \cdots, x_{m j}\right) \quad$ and $Y_{j}=\left(y_{1 j}, y_{2 j}, \cdots, y_{t j}\right)$ denote the input vector and output vector of the Decision Making Unit(DMU) $j ; \lambda_{j}=(j=1,2, \cdots, n)$ denotes the weight vector; $X_{j_{0}}$ and $Y_{j_{0}}$ denote the input and output of DMU $j_{0} ; S^{-}=\left(s_{1}^{-}, s_{2}^{-}, \cdots, s_{m}^{-}\right)$and $S^{+}=\left(s_{1}^{+}, s_{2}^{+}, \cdots, s_{t}^{+}\right)$ denote the Slack variable vector. 


\subsection{Input-output index system}

Applying a DEA model by considering 27 rural 27 rural regions constitutes a analysis of renewable energy in rural China. So, it necessary to set up a input-output system, according to the influence factors of rural renewable energy consumption $^{[7,8]}$. Considering the availability of data, energy consumption and economy, we have work a inputoutput index system, as shown in table 1 .

Table 1 Input-output index system

\begin{tabular}{cc}
\hline type & name \\
\hline Input & Renewable energy \\
index & consumption(Y) \\
\hline & Total consumption of energy(Y1) \\
& Funding (X1) \\
Output & Labor (X2) \\
index & Planting area (X3) \\
& Population (X4) \\
& Consumption level(X5) \\
& Educational level(X6)
\end{tabular}

The energy consists of renewable energy, coal, oil, gas and electricity, among which the renewable energy in rural China consist of straw, biogas, solar energy etc. The funding denotes the investment in renewable energy industry, including government investment and self-funding. The labor denotes the staff in renewable energy industry in rural region, including administrator and technician. The planting area reflects the total area for planting in rural region. Obviously, the population is a index that reflect the residents. The index of consumption level is measured by consumer spending of rural residents. The educational level denotes the educational background of residents, which can reflect the acceptance of residents of renewable energy.

The main data source for this study is the China rural statistical yearbook for the year 2013, China rural energy yearbook for the year 2013 and China energy statistical yearbook for the year 2013 .

\subsection{Pretreatment of index}

In order to uniform the dimension, different types of energy have to be converted into standard coal, base on the conversion coefficient.

$$
S C=\sum E N_{i} \times c_{i}
$$

where $S C$ denote the standard coal; $E N_{i}$ denotes the consumption of energy $i ; c_{i}$ denotes the conversion coefficient of energy $i$.

Table 2 Conversion coefficient

\begin{tabular}{cc}
\hline Energy & conversion coefficient \\
\hline Straw & $0.5(\mathrm{~kg} / \mathrm{kg})$ \\
Biogas & $0.714(\mathrm{~kg} / \mathrm{m} 3)$ \\
Coal & $0.7143(\mathrm{~kg} / \mathrm{kg})$ \\
Oil & $1.429(\mathrm{~kg} / \mathrm{kg})$ \\
Gas & $1.2143(\mathrm{~kg} / \mathrm{m} 3)$ \\
Electricity & $0.12(\mathrm{~kg} / \mathrm{kw} \cdot \mathrm{h})$ \\
\hline
\end{tabular}

The China rural statistical yearbook describes the educational level by indexes including illiteracy, primary school, middle school, Secondary specialized school, junior college. This paper employs the entropy weight method to integrate all indexes that indicate the educational level. The entropy weight method is a comprehensive evaluation method for multi-object and multi-target, which takes the form of eqs.(3)-(7).

$$
\begin{aligned}
& r_{i j}=\frac{r_{i j}^{\prime}-\operatorname{Min}_{i}\left(r_{i j}^{\prime}\right)}{\operatorname{Max}_{i}\left(r_{i j}^{\prime}\right)-\operatorname{Min}_{i}\left(r_{i j}^{\prime}\right)} \\
& r_{i j}=\frac{\operatorname{Max}_{i}\left(r_{i j}^{\prime}\right)-r_{i j}^{\prime}}{\operatorname{Max}_{i}\left(r_{i j}^{\prime}\right)-\operatorname{Min}_{i}\left(r_{i j}^{\prime}\right)} \\
& f_{i j}=r_{i j} / \sum_{i=1}^{27} r_{i j} \\
& H_{j}=-\frac{1}{\ln 27} \sum_{i=1}^{27} f_{i j} \cdot \ln f_{i j} \\
& \omega_{j}=\frac{1-H_{j}}{\sum_{j=1}^{6}\left(1-H_{j}\right)}
\end{aligned}
$$

Eq.(3)-(4) depict the standardization of indexes, while the former applies to the index of illiteracy and the latter applies to the remaining 5 indexes, where $r_{i j}^{\prime}(i=1, \cdots, 27 ; j=1, \cdots, 6)$ denotes the statistical values of indexes of different In eq.(7) shows the calculation of entropy weight of each index.

\section{Analysis results}

\subsection{Correlation analysis}

Since the DEA model must meet the assumption of same orientation, that is, the output can not be reduced with the increase of input ${ }^{[9]}$. In this paper, the Pearson test is adopted to the correlation analysis. As shown in table 3, there is a significant positive correlation between input variables and the output variable. In addition, the findings show that Among the input indicators, consumption level and educational level have a higher correlation with the output index, which indicates that they are the key factors that impact the development of rural renewable energy.

Table 3 Correlations

\begin{tabular}{ccc}
\hline & & Y \\
\hline & Y & 1 \\
& Y1 & $0.690^{* *}$ \\
Pearson & X1 & 0.328 \\
correlation & X3 & 0.149 \\
& X4 & $0.432^{*}$ \\
& X5 & $0.446^{*}$ \\
& X6 & $0.596^{* *}$ \\
\hline
\end{tabular}

\footnotetext{
**. Correlation is significant at the 0.01 level (2-tailed).
}

*. Correlation is significant at the 0.05 level (2-tailed). 


\subsection{Evaluation of renewable energy development}

Renewable energy development evaluation model was solved using the DEAP software. This paper has calculated the comprehensive efficiency, net technical efficiency and scale efficiency of renewable energy in each regions, as shown in table 4. It's indicated that renewable energy development has reached the optimal level, given the existing scale and technology, when the value of comprehensive efficiency is 1 . Otherwise, the development will be proved to lack of efficiency. Then, the comprehensive efficiency is divided into net technical efficiency and scale efficiency, to suggest the reasons that cause the inefficiency. Take Heilongjiang as an example, its value of comprehensive efficiency is 0.371 , which suggests that the development of rural area in Heilongjiang is inefficiency. Furthermore, its values of technical efficiency and scale efficiency are 0.383 and 0.969 respectively. Then, we come to the conclusion that it's the technical efficiency that cause the inefficiency.

Table 4 Efficiency

\begin{tabular}{|c|c|c|c|}
\hline & crste & vrste & scale \\
\hline Beijing & 1 & 1 & 1 \\
\hline Tianjin & 0.149 & 1 & 0.149 \\
\hline Hebei & 0.301 & 0.391 & 0.771 \\
\hline Shanxi & 0.188 & 0.274 & 0.685 \\
\hline Neimenggu & 0.151 & 0.171 & 0.883 \\
\hline Liaoning & 1 & 1 & 1 \\
\hline Jilin & 0.493 & 0.516 & 0.954 \\
\hline Heilongjiang & 0.371 & 0.383 & 0.969 \\
\hline Jiangsu & 1 & 1 & 1 \\
\hline Zhejiang & 0.365 & 0.376 & 0.973 \\
\hline Anhui & 0.616 & 0.649 & 0.95 \\
\hline Fujian & 0.087 & 0.089 & 0.981 \\
\hline Jiangxi & 0.296 & 0.313 & 0.945 \\
\hline Shandong & 0.805 & 0.914 & 0.88 \\
\hline Henan & 0.284 & 0.344 & 0.825 \\
\hline Hubei & 0.448 & 0.51 & 0.878 \\
\hline Hunan & 0.18 & 0.194 & 0.926 \\
\hline Guangdong & 0.063 & 0.065 & 0.971 \\
\hline Guangxi & 0.504 & 0.552 & 0.913 \\
\hline Hainan & 0.599 & 0.627 & 0.956 \\
\hline Chongqing & 0.112 & 0.124 & 0.906 \\
\hline Sichuan & 0.293 & 0.344 & 0.852 \\
\hline Guizhou & 0.128 & 0.15 & 0.85 \\
\hline Yunnan & 0.298 & 0.33 & 0.902 \\
\hline Shanxi & 0.142 & 0.16 & 0.89 \\
\hline Gansu & 0.299 & 0.351 & 0.852 \\
\hline Ningxia & 0.405 & 1 & 0.405 \\
\hline
\end{tabular}

Crste denotes the comprehensive efficiency.

Vrste denotes the technical efficiency.

Scale denotes the scale efficiency.

By comparing the optimal level and actual level of each index to reflect the prospect of the development of renewable energy in different rural regions, as shown in table 5. When the ratio of each index is $100 \%$, the region has reached the optimal state, such as Beijing. Otherwise, the development of renewable energy is inefficient. Take Shanxi as an example, its values of actual output and target output are 62.93 and 229.847 respectively, and the ratio of target output to actual output is $365.22 \%$. Then, we can see a great space for development of renewable energy in rural area of Shanxi.

Table 5 Output targets

\begin{tabular}{cccc}
\hline & Actual( & Target(T & T/A \\
\hline A $)$ & ) & \\
\hline Tianjing & 193.93 & 193.93 & $100.00 \%$ \\
Hebei & 9.08 & 9.08 & $100.05 \%$ \\
Shanxi & 62.93 & 229.847 & $365.03 \%$ \\
Neimenggu & 52.75 & 308.24 & $584.34 \%$ \\
Liaoning & 388.32 & 388.32 & $100.00 \%$ \\
Jilin & 76.83 & 148.81 & $193.68 \%$ \\
Heilongjiang & 117.52 & 307.065 & $261.29 \%$ \\
Jiangsu & 743.43 & 743.43 & $100.00 \%$ \\
Zhejiang & 117.05 & 311.679 & $266.27 \%$ \\
Anhui & 193.51 & 298.29 & $154.15 \%$ \\
Fujian & 24.34 & 273.007 & 1121.46 \\
Jiangxi & 56.78 & 181.563 & $319.74 \%$ \\
Shandong & 679.71 & 743.43 & $109.38 \%$ \\
Henan & 255.60 & 743.43 & $290.86 \%$ \\
Hubei & 246.21 & 482.875 & $196.12 \%$ \\
Hunan & 96.86 & 499.486 & $515.69 \%$ \\
Guangdong & 27.61 & 423.082 & 1532.25 \\
Guangxi & 103.56 & 187.642 & $181.19 \%$ \\
Hainan & 66.52 & 106.124 & $159.54 \%$ \\
Chongqing & 30.39 & 245.939 & $809.23 \%$ \\
Sichuan & 156.82 & 455.954 & $290.76 \%$ \\
Guizhou & 47.62 & 316.571 & $664.84 \%$ \\
Yunnan & 111.45 & 337.276 & $302.62 \%$ \\
Shanxi & 39.27 & 245.404 & $624.84 \%$ \\
Gansu & 92.74 & 263.914 & $284.57 \%$ \\
Ningxia & 25.46 & 25.46 & $100.00 \%$ \\
\hline & & &
\end{tabular}

\section{Conclusion}

This paper has set up a renewable energy development evaluation model, on the basis of which we evaluate the development of renewable energy in 27 rural regions of China with the data of 2010. The findings show that most of rural areas have the problem of inefficiency in the development of renewable energy, which presages a great space for development. Furthermore, there is a significant correlation between input variables, including consumption level and educational level, and the output variable. Consequently, in order to promote the development of renewable energy in rural China, it's essential to develop rural economy and education.

\section{References}

[1] Qi T. The energy and $\mathrm{CO} 2$ emissions impact of renewable energy development in China, Energy Policy, vol.68, 60-69, 2014. 
[2] Zhang X P, Cheng X M, Yuan J H, et al. Total-factor energy efficiency in developing countries, Energy Policy, vol.39, pp.644-650, 2011.

[3] Yeh T L, Chen T Y, Lai P Y.A comparative study of energy utilization efficiency between Taiwan and China, Energy Policy, vol.38, pp.1-8,2010.

[4] Cai X, Xiao X. Study on energy consumption efficiency of China's various regions based on superefficiency DEA, Statistics \& Information Forum, vol.25, pp.33-40, 2010.

[5] Zhang Q, He F, Zhao X. Analysis of Chinese energy efficiency of iron and steel industry based on superefficiency DEA, Soft Science, vol.26, pp.65-68, 2012.

[6] Zhou P, Bai Y. PCA and DEA based comprehensive evaluation on the exploitureof marine renewable energy, Renewable Energy Resources, vol.32, pp.120-126, 2014.

[7] Xia Y, Yang C,Chen X. Analysis on determining factors of energy intensity in China based on comparable price input-output table,Systems Engineering-Theory \&Practice, vol.29, pp.22-27, 2009.

[8] Hu X, Yang L. Analysis of growth differences and convergence of regional green TFP in China, Journal of Finance and Economics, vol.37, pp.23-134,2011.

[9] Liu Y, Hu Z. Research on regional difference about carbon emission efficiency in China-based on three stage DEA model and super efficiency DEA Model, Journal of Shanxi University of Finance and Economics, vol.37, pp.23-34, 2015. 